Available online at www.eccomasproceedia.org

Eccomas Proceedia COMPDYN (2021) 1212-1222

ECCOMAS

Proceedia
COMPDYN 2021

$8^{\text {th }}$ ECCOMAS Thematic Conference on Computational Methods in Structural Dynamics and Earthquake Engineering M. Papadrakakis, M. Fragiadakis (eds.) Streamed from Athens, Greece, 28 - 30 June 2021

\title{
OUT-OF-PLANE TESTING OF MASONRY INFILL WALLS MADE WITH LIGHTWEIGHT CONCRETE BLOCKS
}

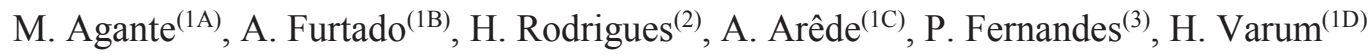 \\ ${ }^{1}$ CONSTRUCT-LESE, Faculdade de Engenharia da Universidade do Porto \\ Porto, Portugal \\ e-mail: A - up201700035@edu.fe.up.pt, B - afurtado@fe.up.pt, C - aarede@fe.up.pt and D - \\ hvarum@fe.up.pt \\ ${ }^{2}$ RISCO, Universidade de Aveiro \\ Aveiro, Portugal \\ hrodrigues@ua.pt \\ ${ }^{3}$ Instituto Politécnico de Leiria \\ Leiria, Portugal \\ paulo.fernandes@ipleiria.pt
}

\begin{abstract}
The masonry infill walls are widely spread over the reinforced concrete buildings due to different demands. The buildings' thermal energy efficiency is a top priority nowadays since many of the existing building stock comprises buildings with low energy performance. The buildings' external envelope is suffering a transformation with the appearance of the vertical hollow concrete blocks with high thermal and acoustic demands. However, recent evidence from a strong earthquake shows that the masonry infill walls are vulnerable to out-of-plane loadings and were responsible for many casualties, injuries, and economic losses. Based on that, this work's main objective is to study the out-of-plane (OOP) behaviour of masonry infills made with vertical hollow concrete blocks. The experimental campaign comprises the OOP testing of three full-scale infill walls made up of these masonry units. One of them was as-built without previous damage, one with previous damage due to an earlier in-plane test and the third one retrofitted. All the tests consisted of applying the loading-unloadingreloading history of imposed displacements in the OOP direction through a uniformly distributed load. The results will be presented in terms of OOP force-displacement responses, deformed shapes, damage evolution, energy dissipation capacity and damping. Finally, the test results are compared to each other to assess the previous damage and the retrofit technique's effectiveness.
\end{abstract}

Keywords: Masonry infill walls, Out-of-plane behaviour, lightweight concrete blocks, Experimental testing. 


\section{INTRODUCTION}

Masonry infill walls are widely spread over the reinforced concrete (RC) building structures. Different masonry units were developed over the years to be used to construct the RC buildings envelopes. Their geometric, thermal and acoustic characteristics followed the building code demands, neglecting the vulnerability's assessment under out-of-plane (OOP) seismic loadings. At the beginning of 1950, hollow clay horizontal bricks with different thicknesses $(70 \mathrm{~mm}, 110 \mathrm{~mm}, 150 \mathrm{~mm}$ and $220 \mathrm{~mm})$ and at the 2000 decade, clay and concrete vertical thermal blocks were developed. Their acoustic and thermal characteristics were improved to be used in the buildings façade. However, experimental studies on the seismic behaviour of lightweight concrete blocks are very scarce.

Different investigations were carried out concerning the OOP behaviour of masonry infill walls $[1,2]$, from which it was concluded that the OOP strength reduces with the increasing of the panel slenderness [3, 4]. Ricci, et al. [4] performed a series of OOP tests assessing the effect of the walls slenderness in their OOP behaviour. Before the OOP tests, the walls were subjected to different IP damage levels (Low $-0.30 \%$; Medium $-0.60 \%$ and High $-1 \%$ ). Hollow clay horizontal units were used to construct the scaled walls with slenderness equal to 22.9 and 15.2. It was observed during the tests a more significant decrease of the OOP maximum strength and initial stiffness for the thinner panels.

De Risi, et al. [5] carried out a testing campaign to study the effect of the panel aspect ratio (1.28 and 1) in their OOP response. The authors found that square and rectangular infills have very different damage states. For examples, the rectangular walls showed more damage than square ones. For panels previously subjected to low IP drift $(0.30 \%)$, the square panel exhibited a strength reduction of $24 \%$, while the rectangular panel reduced by about $52 \%$.

Based on this motivation, this research work's primary goal was to study the OOP behaviour of full-scale masonry infill walls made with lightweight concrete blocks. An experimental campaign was carried out comprising three full-scale specimens. The first specimen was tested without previous damage and without strengthening. The second specimen was tested with prior damage caused by a previous IP test with a maximum drift of $0.3 \%$ without strengthening. The third wall was tested without previous damage, but it was strengthened with a TRM based solution. All the tests have been performed by imposing a half-cyclic (loadingunloading-reloading) history of displacements in the OOP direction employing a uniform distributed load provided by small pneumatic jacks. The results will be presented in terms of damage evolution and OOP force-displacement responses.

\section{DESCRIPTION OF THE TESTING CAMPAIGN}

\subsection{Specimens characteristics}

A full-scale RC frame was built in a laboratory $4.80 \mathrm{~m}$ long and $3.30 \mathrm{~m}$ high and was designed according to Eurocode 8 - Part 1 [6] for medium ductility class. The columns dimensions are $0.30 \times 0.30 \mathrm{~m} 2$ with longitudinal reinforcement $4 ø 16+2 ø 12$ and transversal reinforcement equal $\varnothing 8 / / 0.05 \mathrm{~m}$ along the plastic hinge regions and $\varnothing 8 / / 0.15 \mathrm{~m}$ in the remaining extension of the column. Regarding the beam cross-section detailing, it was defined to be $0.30 \mathrm{x} 0.50 \mathrm{~m} 2$ with symmetrical longitudinal reinforcement of $5 \varnothing 16+5 \varnothing 16$ and transversal reinforcement of $\varnothing 8 / / 0.10 \mathrm{~m}$ along the plastic hinge length and $\varnothing 8 / / 0.20 \mathrm{~m}$ in the remaining beam extension. The dimensions and detailing of the frame are presented in Figure 1. 


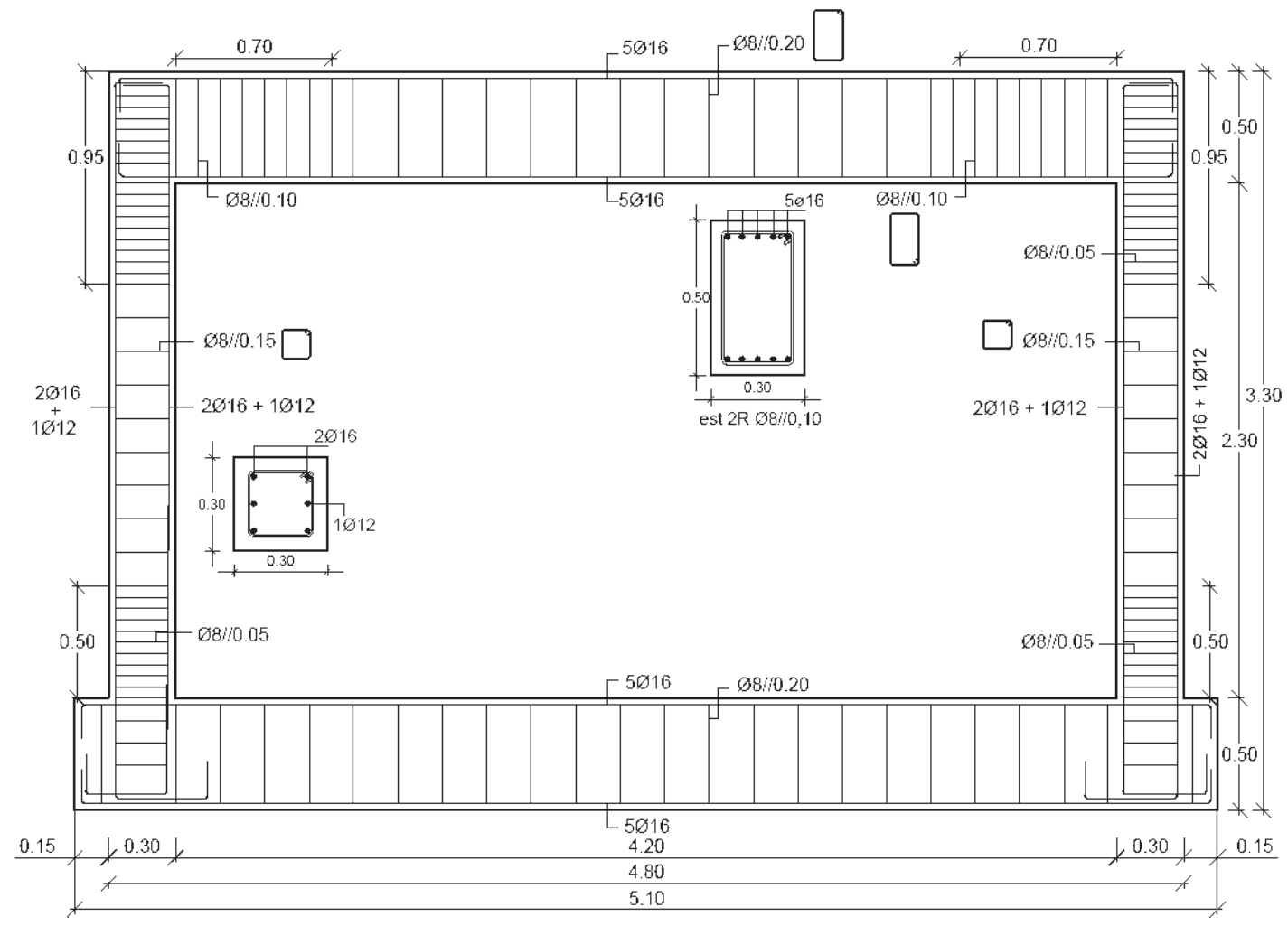

Figure $1-\mathrm{RC}$ frame dimensions and detailing.

The masonry infill walls were constructed with vertical hollow concrete blocks. These light lightweight concrete blocks (Figure 2) of expanded clay aggregates have the nominal dimensions of $400 \times 190 \times 315 \mathrm{~mm}^{3}$. The thermal transmission coefficient $(\mathrm{U})$ is $0.51 \mathrm{~W} / \mathrm{m}^{2 \circ} \mathrm{C}$ and were specially designed for simple exterior walls or in contact with unheated areas. It can also be used in partitions between fires, stairwells and elevators. Vertical compressive strength tests were carried out in masonry units according to the standard EN 772-1 [7].

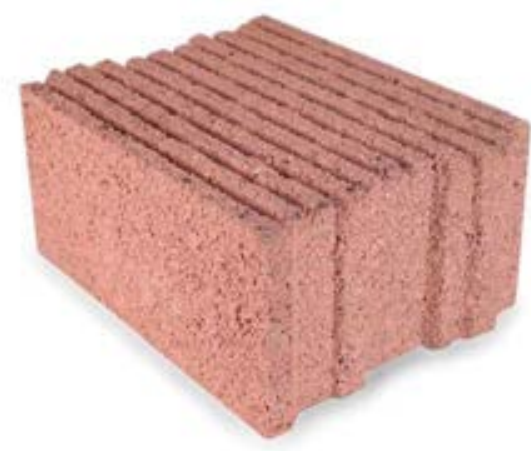

a)

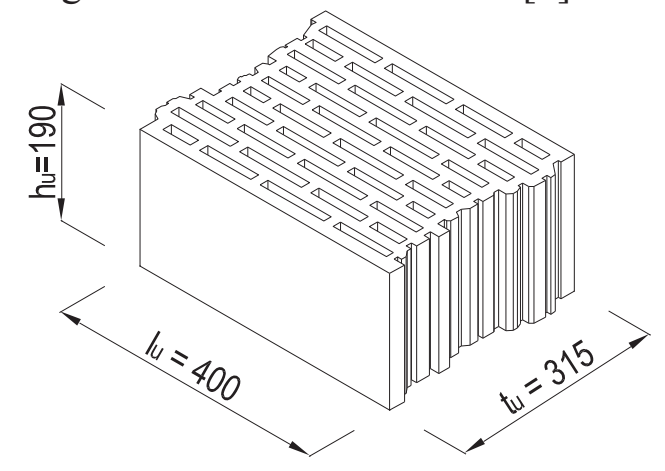

b)

Figure 2 - Detail of the masonry unit: a) general overview; and b) geometric details (units in millimetres).

All the panels have the same geometrical dimensions, boundary conditions and materials. The construction of each wall started with the placement of a continuous layer of mortar over the entire width of the previously humidified frame. The blocks were then placed and positioned. The masonry infill walls were aligned with the external surface of the RC frame. Due to that, a short portion of the masonry infill walls remained $15 \mathrm{~mm}$ from the frame's back face (the thickness of the block is $315 \mathrm{~mm}$, and the beam width is $300 \mathrm{~mm}$ ). Discontinuous bed joints 
approximately $15 \mathrm{~mm}$ thick were placed using a mortar box provided by the supplier. This procedure was repeated until it was impossible to fit another row of blocks, leaving about 130 $\mathrm{mm}$ between the panel and the lower face of the RC frame's upper beam to be filled. It was decided to close the masonry panel two or three days after its construction to guarantee stabilization in the deformation of the wall during the mortar curing, ensuring the sealing between the upper face of the masonry and the upper beam of the frame. An M5 class mortar was used to build the masonry infill walls. Vertical bed joints with $10 \mathrm{~mm}$ thickness were assumed between the concrete masonry units.

As mentioned before, the specimens LWC_Ref and LWC_IPOOP were built with the same characteristics. The third wall LWC_S was strengthened with TRM. The reinforcing mesh was applied only on one side of the wall. The strengthening consisted of using a glass fibre textile mesh with a matrix of $4 \times 4 \mathrm{~cm}$ and a tensile strength equal to $70 \mathrm{kN} / \mathrm{m}^{2}$. The construction process started with the first layer of plaster $(0.5 \mathrm{~cm}$ thick) over the whole panel and $12 \mathrm{~cm}$ in length and the RC elements. For this plaster, it was used an M10 mortar. After that, the textile mesh was placed and fixed to the panel using plastic connectors. These connectors were set all over the wall with a geometry defined in Figure 6. Also, the mesh was anchored to the RC elements using thin steel plates and steel connectors M8. According to the supplier recommendations, a textile mesh overlapping with a total length of $100 \mathrm{~mm}$ was used. The interface wall-RC frame was used to layers of stripes with a full extension in the columns and beams of $170 \mathrm{~mm}$ and the panel of $400 \mathrm{~mm}$, in agreement with the standard ACI $5494 \mathrm{R}$ recommendations. After applying the textile mesh, a second layer of mortar $(1 \mathrm{~cm})$ was applied. The schematic lavout of the I.WC S strenothino is nresented in Fioure 3

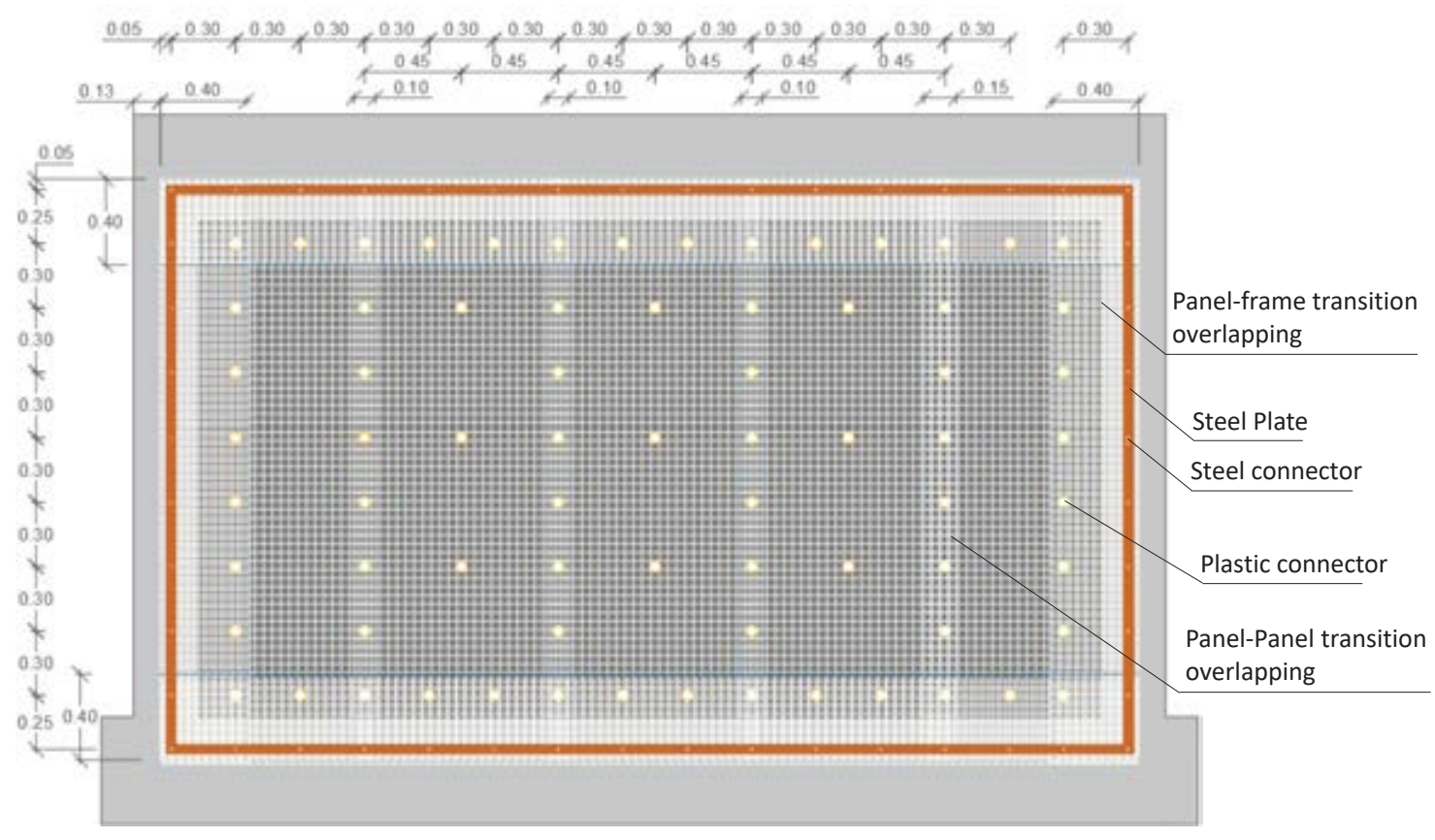

Figure 3 - Schematic layout of the strengthening solution of the wall LWC_S.

\subsection{Description of the in-plane and out-of-plane test setup}

The quasi-static IP cyclic test consisted of applying a horizontal force at half the height of the $\mathrm{RC}$ frame's upper beam through a hydraulic actuator with a capacity of approximately $500 \mathrm{kN}$ and $+/-150 \mathrm{~mm}$ travel. The hydraulic actuator is connected to a steel reaction structure. The 
horizontal force transmission to ensure full-cycle tests were performed using two steel profiles positioned on the top beam's extremities linked together through four dywidag prestressed bars $(\varnothing 27 \mathrm{~mm})$, resulting in a beam compression of about $170 \mathrm{kN}$. The quasi-static cyclic test schematic layout is shown in Figure 4. A steel structure was used at the back of the $\mathrm{RC}$ frame, linked in two points of the frame top beam. The primary goal was to avoid OOP displacement or rotation of the structure during the test. The frame's base IP and OOP displacement were restricted using a steel profile attached to the strong slab.

The IP drift ratio was computed using the displacement of the top beam-column joint divided by the distance between the bottom and top beam-column joints. The IP displacement of the bottom beam-column joint is subtracted from the displacement of the top beam-column joint to avoid possible frame sliding effect.

The quasi-static IPcyclic loading consisted of applying a horizontal load at half-height of the RC frame upper beam, in the form of target displacements until a drift of $0.3 \%$. Each cycle started with an increase in loading until reaching the target displacement and after unloading the inverse target, displacement was applied, ending after unloading. Three target displacements 2.8, 5.6 and $8.4 \mathrm{~mm}$ were imposed, corresponding to $0.1 \%, 0.2 \%$ and $0.3 \%$ drift, respectively, with three repetition cycles for each target displacement, totalling nine complete cycles.

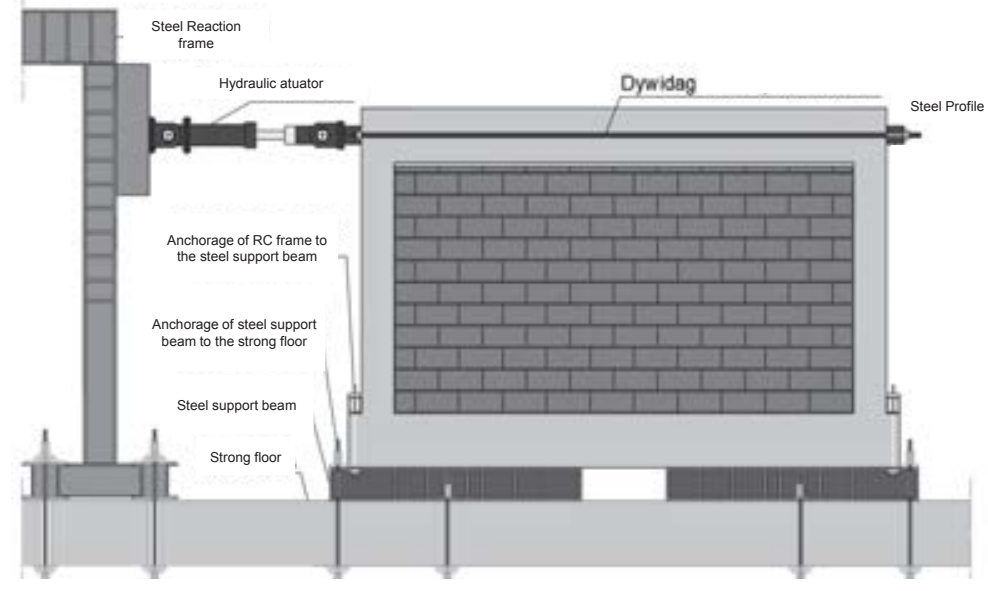

a)

Figure 4 - Schematic layout of the IP test setup.

The OOP test consisted of applying a distributed OOP loading through twenty-eight pneumatic actuators that mobilize the entire infill panel surface resorting to wood plates (one per actuator) placed between the actuators and the panel. The maximum strength capacity of each pneumatic actuator is $20 \mathrm{kN}$ and a total displacement amplitude of $185 \mathrm{~mm}$. The system has a full-strength ability to apply a distributed load of $560 \mathrm{kN}$. This testing platform can test infill panels with openings (with different configurations and dimensions). This test setup also allowed placing the instrumentation in the back of the reaction structure, which helps to perform OOP tests until the panel collapse without damaging any equipment. Identifying the panels' cracking throughout the OOP tests becomes easier as the quality of the pictures and films recording of each test improved significantly. A self-equilibrated system was used, which balances the transmission of the OOP loadings to the reaction frame attached to the RC frame. Thus, this test setup uses pneumatic jacks linked to four horizontal alignments performed by HEB140 steel profiles, which react against five vertical alignments made of 
HEB200 steel profiles. The horizontal alignments are coupled with hinged devices that allow lateral sliding. The steel structure is attached to the $\mathrm{RC}$ frame in twelve points $(5$ in the bottom beam, 5 in the top beam, and 2 in middle-height columns) with steel bars coupled with load cells to monitor the OOP loadings. Figure 5a and Figure $5 \mathrm{~b}$ present the schematic layout and the general view of the test setup. The pneumatic actuators applied the OOP loading, and the test control is ensured by monitoring their internal pressure and the imposed OOP displacements in a selected control point.

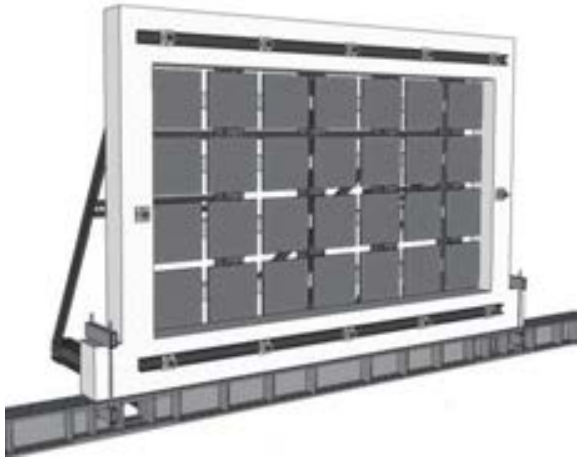

a)

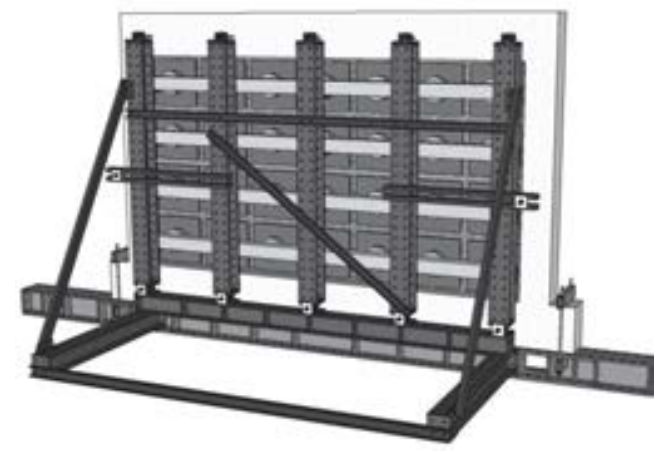

b)

Figure 5 - Layout of the OOP test setup using pneumatic actuators: a) front and b) near view.

The loading protocol is based on the protocol used in the previous tests [8] and consisted of the application of several half-cyclic OOP displacements (loading-unloading-reloading) that were imposed with steadily increasing displacement levels, targeting the following nominal peak displacements at the control node located in the centre of the panel: $0.5,1,1.5,2,2.5$, $3.5 ; 5 ; 7.5 ; 10 \mathrm{~mm}$; and then 5 by $5 \mathrm{~mm}$ up to a maximum OOP displacement of $120 \mathrm{~mm}$ (largest capacity of the pneumatic actuators). Two half-cycles were repeated for each lateral deformation demand level. No axial load was applied on the top of the adjacent RC columns.

\section{DISCUSSION OF THE EXPERIMENTAL RESULTS}

\subsection{Individual results}

\subsubsection{Specimen LWC_Ref}

The undamaged and no-strengthened specimen LWC_Ref was tested under OOP loadings and reached the first cracking for a DROOP,crack of $0.29 \%$ and a corresponding force equal to $76.75 \mathrm{kN}$. The cracking was located at the panel centre and is horizontal with a full-length extension of $2 \mathrm{~m}$. The initial stiffness was estimated at $24024 \mathrm{kN} / \mathrm{m}$. After that, diagonal cracking emerged from the horizontal first one to both bottom corners of the panel. A vertical crack was also visible at the panel middle length, from the horizontal first crack to the panel's top. This cracking configuration is similar to trilinear cracking, which typically corresponds to a wall with three borders constrained, and the top boundary is unrestricted or less restricted. This phenomenon is justified by the quality and type of construction of the wall last row (top beam-panel interface), which was mortared. Similar observations were reported in the literature by other authors $[8,9]$.

At this stage, the specimen reached the maximum peak load of about $229.6 \mathrm{kN}$ for a DRoop,max equal to $4.19 \%$. When compared with the first cracking stage, it is possible to observe that the peak load and the OOP drift are 3 and 14.4 times higher, respectively. Afterwards, the panel reduced its OOP strength slightly until reaching the OOP drift of $6 \%$ in which occurred a large detachment of the panel from the top beam and a slight separation from the bottom 
beam. New oblique cracks appeared. Horizontal and vertical cracks became thicker and crack developed at the bottom panel-frame interface, presenting a crack pattern maintained until the end of the test. Upon reaching the DRoop,ult of $7.63 \%$ with a residual strength of $149.2 \mathrm{kN}$. The panel exhibited an increase of detachment concerning the upper and lower beams of the frame and presented new vertical cracks in the panel's centre. Based on the measurements made by the vertical displacement located at the top of the frame structure and based on this cracking pattern, it can be concluded that the arching mechanism controlled the response of the wall. Two-way bending occurred similarly to a panel three borders constrained. The top panelframe interface was not fully mortared due to difficulties in the wall constructions, which is quite common in constructing infill walls, as observed in previous research works $[5,8,10]$. Finally, it can be stated that the conventional rupture occurred for an OOP drift of $6.94 \%$. The force-displacement curve is presented in Figure 6a. The damages observed at the end of the test are shown in Figure 6b.

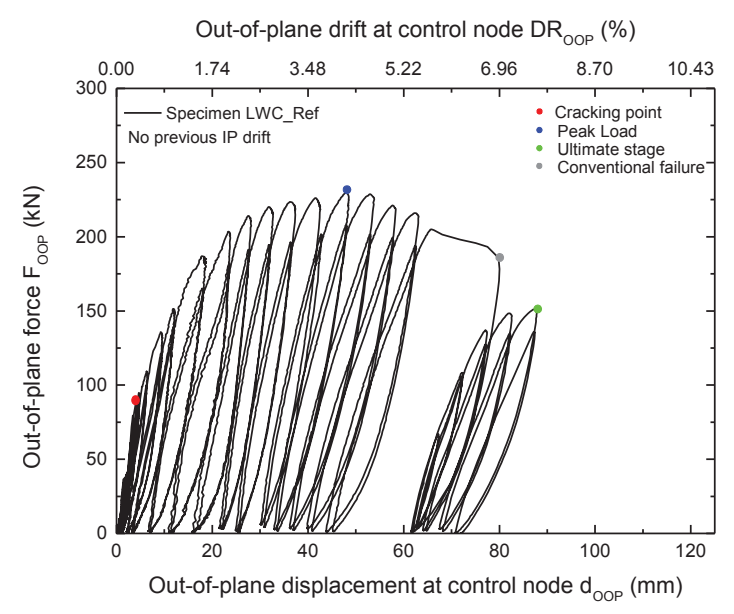

a)

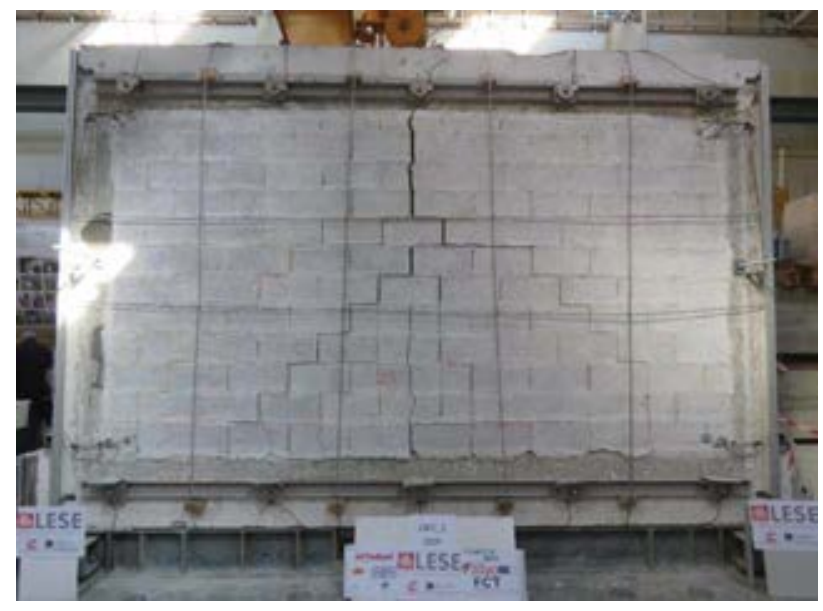

b)

Figure 6 - Specimen LWC_Ref: a) Force-displacement curve; Damages observed at the end of test and b) Front view.

\subsubsection{Specimen LWC_IPOOP}

The out-of-plane load was applied after the in-plane test, in agreement with the protocol described before. From the test, it is was observed that the first crack occurred for a DRoop,crack equal to $0.71 \%$ and a corresponding force of $204.4 \mathrm{kN}$. The first crack appeared horizontally, followed by two oblique cracks up to the panel's lower corners. The initial panel stiffness was $60427 \mathrm{kN} / \mathrm{m}$. After that, the peak load was reached for a value equal to $246.06 \mathrm{kN}$ and a corresponding drift of $1.39 \%$. A vertical crack appeared at the top of the panel, and horizontal cracks develop in this stage. The OOP strength remains almost constant until $2.3 \%$, when it started to reduce progressively. The conventional rupture was reached for an OOP drift equal to $3.87 \%$.

After that, the panel rupture occurred through the vertical sliding and cracking of the concrete blocks from the panel upper part. The separation of the panel into two pieces resulting from the arching mechanism development becomes more evident. The trilinear cracking pattern was observed at the test end for a DROOP,ult equal to $4.77 \%$ and a residual force of $155.9 \mathrm{kN}$. Based on the measurements made by the vertical displacement located at the top of the frame structure and based on this cracking pattern, it can be concluded that the arching mechanism controlled the response of the wall. Again, two-way bending occurred similarly to a panel three borders constrained, as observed in previous research works $[5,8,10]$. Figure 7 a shows 
the force-displacement curve. The damages observed after the end of the test are shown in Figure $7 b$.

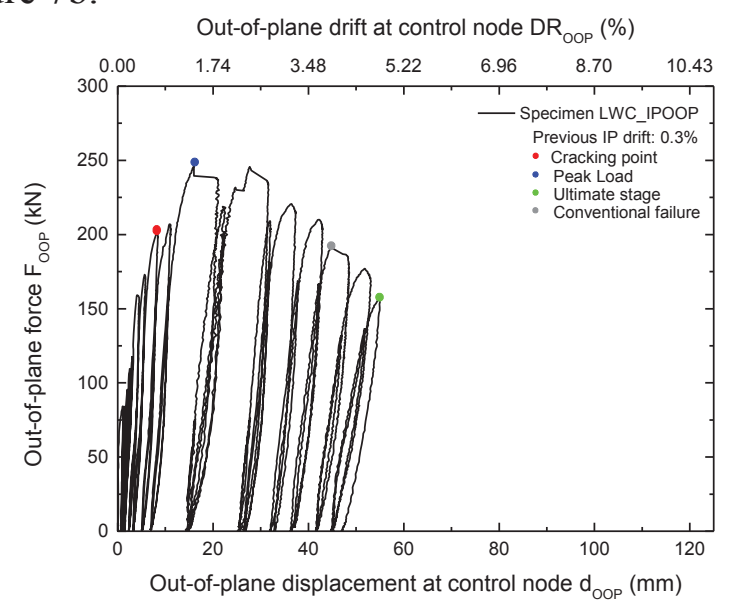

a)

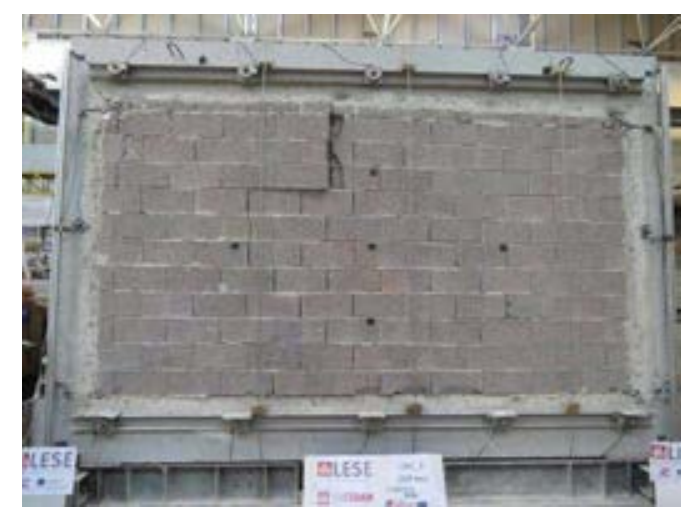

b)

Figure 7 - Specimen LWC_IPOOP: OOP test a) Force-displacement curve; Damages observed at the end of test b) front view.

\subsubsection{Specimen LWC_S}

The strengthened panel LWC_S was subjected to a pure OOP test and presented an initial stiffness equal to $69250 \mathrm{kN} / \mathrm{m}$. The development of the first visible horizontal cracks occurred for a DROOP,crack equal to $0.30 \%$ for a corresponding force of $171.3 \mathrm{kN}$. The OOP force increased to values around $280 \mathrm{kN}$ and remained almost constant until reaching the maximum value of $281.28 \mathrm{kN}$ for a drift of $2.76 \%$. The panel detached from the upper beam during this period and developed a vertical crack in the panel's upper part. The first diagonal cracks appear. The vertical crack is more evident at the peak stage, and new vertical cracks occur at the panel's top and bottom. Horizontal cracks become thicker, and cracks develop at the interface between the panel and the frame. After that, there is a sudden reduction of the OOP force of about $25 \%$ for a drift of $3.1 \%$. The degradation of the OOP strength was then slow until reaching the conventional collapse for the drift of $6.17 \%$. At this moment, it occurred again, a reduction of the panel strength of about $20 \%$ for a $6.82 \%$ of drift. After that, the panel strength was continuously reducing until the last stage, where it was observed the sliding of the glass fibers of the reinforcement mesh from the steel plate. The residual panel strength was $103.57 \mathrm{kN}$ for a drift of $8.21 \%$. Based on the measurements made by the vertical displacement located at the top of the frame structure and based on this cracking pattern, it can be concluded that the arching mechanism controlled the response of the wall. Again, two-way bending occurred similarly to a panel three borders constrained. The force-displacement curve is plotted in Figure 8a. The damages observed after the end of the test are shown in Figure 8b. 


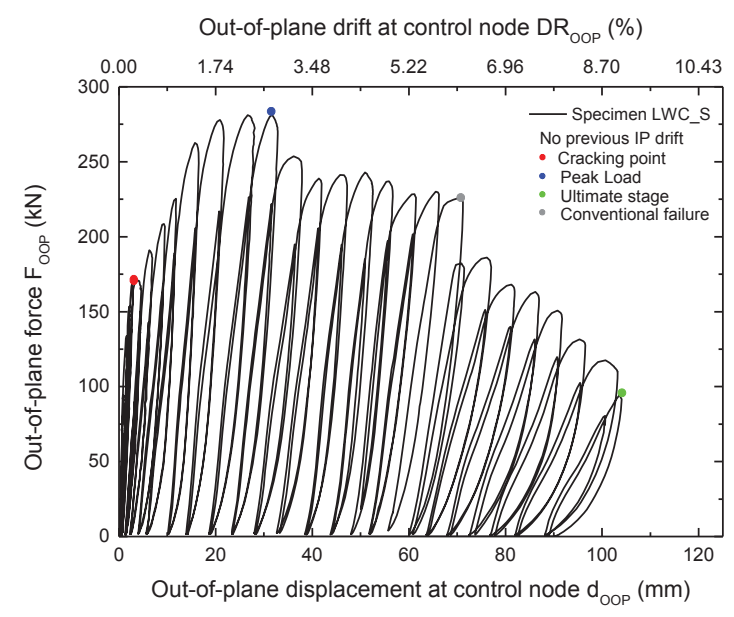

a)

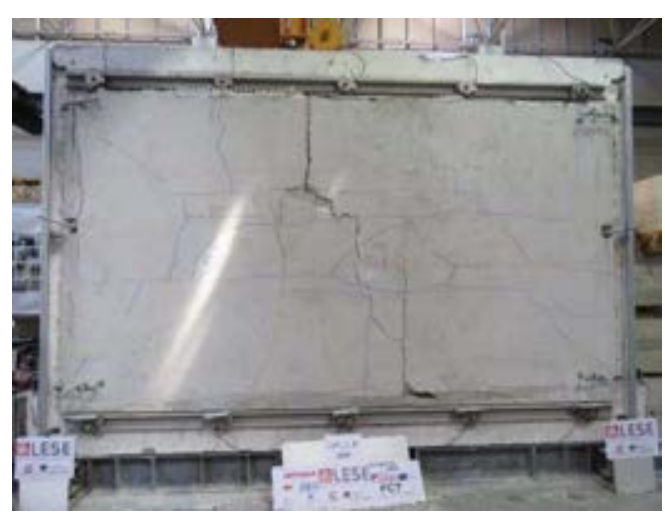

b)

Figure 8 - Specimen LWC_S: a) Force-displacement curve; Damages observed at the end of the test; b) Front view.

\subsection{Global results comparison}

The initial secant stiffness, kOOP,sec,ini, was calculated for each specimen by dividing the peak load of the first half-cycle by the respective OOP displacement. It can be observed that the LWC_S reached, as expected, the highest one. The initial stiffness of the panel LWC_S is 2.88 times higher than LWC_Ref and 14\% than LWC_IPOOP. Surprisingly, LWC_IPOOP got an initial stiffness 2.52 times higher than LWC_Ref. Since this panel was damaged before the OOP test due to the IP test, it was expected that the initial stiffness would be lower than LWC_Ref. Based on this, and since no other experimental evidence can justify this result, this higher initial stiffness of LWC IPOOP can only be attributed to experimental variability.

Regarding the first cracking development, the lowest $\mathrm{DR}_{\text {oop,crack was }} 0.29 \%$, and LWC_Ref reached it. The highest $\mathrm{DR}_{\text {oop, crack was }} 0.71 \%$ achieved by the LWC_IPOOP, 2.44 times higher than LWC_Ref. The previous damage was the reason that justifies this significant variation. The cracks developed in the IP test widened and the other ones only emerged for a larger OOP drift demand. The TRM strengthening increased the $\mathrm{DR}_{\text {oop,crack }}$ by about $3.4 \%$. Concerning the $\mathrm{F}_{\text {oop,crack, }}$ LWC_IPOOP and LWC_Ref again reached the highest and lowest result with $204.4 \mathrm{kN}$ and $7 \overline{6} .8 \mathrm{kN}$, respectively. Experimental variability can justify can that LWC_IPOOP DR oop,crack was 2.66 times higher than LWC_Ref. The strengthening increased the $\mathrm{F}_{\text {oop,crack }}$ about 2.23 times.

The maximum peak load was reached by the strengthened specimen LWC_S with $281.3 \mathrm{kN}$, proving the technique's efficiency to increase the wall strength capacity. $\mathrm{L} \overline{\mathrm{W}} \mathrm{C}$ Ref achieved the lowest peak load with $229.6 \mathrm{kN}$. The TRM strengthening increased the strength capacity about $23 \%$, but it occurred for a $\mathrm{DR}_{\text {oop,max. }} .35 \%$ lower. The previously damaged LWC_IPOOP reached a $\mathrm{F}_{\text {oop,max }} 7 \%$ higher than the reference one due to variability often observed in experimental tests [4]. The $\mathrm{DR}_{\text {oop,max }}$ of the specimen LWC_IPOOP was $77 \%$ lower than the reference specimen.

The conventional rupture occurred first for the specimen LWC_IPOOP $\left(\mathrm{d}_{\text {oop,conv }}\right.$ equal to $3.87 \%$ ), highlighting the importance of previous damage in reducing the OOP capacity. The $\mathrm{DR}_{\text {oop,conv }}$ of the specimen LWC_REF was two times higher than LWC_IPOOP. The strengthening solution did not contribute to the increase of the $\mathrm{DR}_{\text {oop,conv }}$, since the panel LWC_S reached the conventional rupture at $6.17 \%, 11 \%$ lower than the reference specimen. However, the residual strength capacity was $22 \%$ higher. 
No reliable conclusions can be extracted from the ultimate stage since the tests were interrupted for different OOP displacement demands depending on the level of damage.

Table 1 - Global results comparison.

\begin{tabular}{|c|c|c|c|}
\hline Parameters & LWC_Ref & LWC_IPOOP & LWC_S \\
\hline kOOP,sec,ini $(\mathrm{kN} / \mathrm{mm})$ & 24024 & 60427 & 69250 \\
\hline FoOP,crack $(\mathrm{kN})$ & 76.75 & 204.41 & 171.3 \\
\hline FoOP,max $(\mathrm{kN})$ & 229.6 & 246.06 & 281.3 \\
\hline FOOP,conv $(\mathrm{kN})$ & 183.7 & 196.3 & 225 \\
\hline FOOP,ult $(\mathrm{kN})$ & 149.2 & 155.92 & 103.6 \\
\hline DRoOP,crack $(\%)$ & 0.29 & 0.71 & 0.30 \\
\hline DROOP,max $(\%)$ & 4.19 & 1.39 & 2.76 \\
\hline DROOP,conv $(\%)$ & 6.94 & 3.87 & 6.17 \\
\hline DROOP,ult $(\%)$ & 7.63 & 4.77 & 8.21 \\
\hline
\end{tabular}

\section{CONCLUSIONS}

This manuscript's primary goal was to study the OOP behaviour of full-scale masonry infill walls made with lightweight concrete blocks. An experimental campaign was carried out comprising three nominally identical full-scale specimens were built. One of them without previous damage and without strengthening. The second specimen was tested with prior damage caused by a prior IP test with a maximum drift of $0.3 \%$ without strengthening. The third wall was tested without previous damage, but it was strengthened with a TRM based solution. All the tests have been performed by imposing a half-cyclic (loading-unloading-reloading) history of displacements in the out of plane (OOP) direction employing a uniform distributed load provided by small pneumatic jacks. From the testing campaign, the following conclusions can be drawn:

$>$ The previous damage increased the displacement corresponding to the first crack development. On the other hand, the strengthening reduced this cracking displacement. The same phenomenon was observed at the peak load, and conventional rupture stages. It should be taken into account the variability often observed in experimental tests;

$>$ The OOP strength capacity was not affected by the previous damage, which can be associated with experimental variability. A minor increase of the panel peak load was also observed when strengthened with TRM compared with the reference specimen. Globally, it can be stated that the IP damage and strengthening affect the ductility in negative and positive manners. Only three tests were carried out to assess both effects, which are not enough to draw solid conclusions. Additional tests need be carried out to validate the findings herein extracted;

The TRM strengthening provided no significant improvement in all the response parameters. Besides the use of a textile mesh with high tensile strength, the strength capacity was not improved. Even the strength degradation was similar to the reference specimen. 


\section{ACKNOWLEDGMENTS}

This work was financially supported by: Base Funding - UIDB/04708/2020 and Programmatic Funding - UIDP/04708/2020 of the CONSTRUCT - Instituto de I\&D em Estruturas e Construções - funded by national funds through the FCT/MCTES (PIDDAC). In addition, this work was also supported by the Foundation for Science and Technology (FCT) - Aveiro Research Centre for Risks and Sustainability in Construction (RISCO), Universidade de Aveiro, Portugal [FCT/UIDB/ECI/04450/2020].

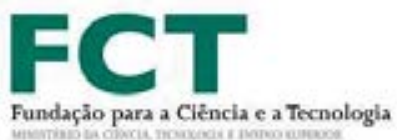

\section{arvinca PORTUGUESA}

\section{REFERENCES}

[1] A. Furtado, H. Rodrigues, A. Arede, and H. Varum, "Experimental Investigation on the Possible Effect of Previous Damage, Workmanship and Test Setup on the Out-ofplane Behaviour of Masonry Infill Walls," Journal of Earthquake Engineering, pp. 132, 2021.

[2] A. Furtado and M. Teresa de Risi, "Recent Findings and Open Issues concerning the Seismic Behaviour of Masonry Infill Walls in RC Buildings," Advances in Civil Engineering, vol. 2020, p. 9261716, 2020/03/13 2020.

[3] J. Dawe and C. Seah, "Behaviour of masonry infilled steel frames," Canadian Journal of Civil Engineering, vol. 16, pp. 865-876, 1989.

[4] P. Ricci, M. Di Domenico, and G. M. Verderame, "Experimental investigation of the influence of slenderness ratio and of the in-plane/out-of-plane interaction on the outof-plane strength of URM infill walls," Construction and Building Materials, vol. 191, pp. 507-522, 2018/12/10/2018.

[5] M. T. De Risi, M. Di Domenico, P. Ricci, G. M. Verderame, and G. Manfredi, "Experimental investigation on the influence of the aspect ratio on the in-plane/out-ofplane interaction for masonry infills in RC frames," Engineering Structures, vol. 189, pp. 523-540, 2019/06/15/2019.

[6] Eurocode 8: Design of structures for earthquake resistance - Part 1-1: General rules, seismic actions and rules for buildings, B. European Committee for Standardization, Belgium, 2005.

[7] CEN, "NP-EN 772-1 Métodos de ensaio de bolocos para alvenaria Parte 1: Determinação da resistência à compressão," 2002.

[8] A. Furtado, H. Rodrigues, A. Arêde, and H. Varum, "Effect of the Panel Width Support and Columns Axial Load on the Infill Masonry Walls Out-Of-Plane Behavior," Journal of Earthquake Engineering, Article vol. 24, no. 4, pp. 653-681, 2020.

[9] F. Akhoundi, G. Vasconcelos, and P. Lourenço, "Experimental Out-Of-Plane Behavior of Brick Masonry Infilled Frames," International Journal of Architectural Heritage, Article vol. 14, no. 2, pp. 221-237, 2020.

[10] M. T. De Risi et al., "Experimental analysis of strengthening solutions for the out-ofplane collapse of masonry infills in RC structures through textile reinforced mortars," Engineering Structures, vol. 207, p. 110203, 2020/03/15/ 2020. 